\title{
Microstructures and Microsegregation of Directionally Solidi- fied Mg-1.5Gd Magnesium Alloy with Different Growth Rates
}

\author{
Wang Jia'an ${ }^{1}$, Wang Jiahe ${ }^{2}$, Song Zhongxiao ${ }^{3}$ \\ China Huadian Electric Power Research Institute, Hangzhou 310030, China; ${ }^{2}$ State Key Laboratory of Solidification Processing, \\ Northwestern Polytechnical University, Xi'an 710072, China; ${ }^{3}$ Xi'an Jiaotong University, Xi'an 710049, China
}

\begin{abstract}
Directional solidification of Mg-1.5Gd (wt\%) magnesium alloy was carried out to investigate the effects of the growth rate on the microstructures under controlled solidification conditions. A Bridgman-type directional solidification furnace with a liquid metal cooling (LMC) technique was used to solidify the specimens, which could provide steady state conditions with a constant temperature gradient $(40 \mathrm{~K} / \mathrm{mm})$ at a wide range of growth rate $(10 \sim 200 \mu \mathrm{m} / \mathrm{s})$. Results show that the microstructures are cellular, and the relationship between cellular spacing $(\lambda)$ and growth rate $(V)$ is established in the form: $\lambda=130.2827 V^{0.2228}$ by a linear regression analysis, which is in good agreement with the calculated values by Trivedi model. The thermodynamics solidification path calculations by Scheil model and experimental observations confirm that the solidification microstructure in the alloy consists of primary $\alpha(\mathrm{Mg})$ phase and binary eutectic $\alpha(\mathrm{Mg})+\mathrm{Mg}_{5} \mathrm{Gd}$ phase. Meanwhile, the microsegregation of the alloying element predicted by the Scheil model agrees reasonably with the electron probe microanalysis (EPMA) measurements.
\end{abstract}

Key words: Mg-1.5Gd magnesium alloy; directional solidification; microstructures; cellular spacing; microsegregation

In view of their low density, high stiffness, high specific strength and excellent damping performance, magnesium alloys have a wide application prospect in the fields of aerospace, military industry, automobile, electronics etc. ${ }^{[1]}$. Compared with aluminum alloys, however, the strength of magnesium alloys is still relatively low which limits their extensive application. To improve the mechanical properties of $\mathrm{Mg}$ alloys, $\mathrm{Mg}$ - $\mathrm{RE}$ (rare-earth elements, such as $\mathrm{Gd}, \mathrm{Y}, \mathrm{Nd}$, etc.) alloys have been given tremendous attention due to their high specific strength at both room and elevated temperatures as well as their excellent creep resistance ${ }^{[2-8]}$. Among them, $\mathrm{Mg}-\mathrm{Gd}$ system is one of the promising candidates for a novel Mg-based heat-resistant alloy. Drits ${ }^{[9]}$, Rokhlin ${ }^{[10]}$ and Shigeharu ${ }^{[11]}$ et al. investigated the mechanical properties of $\mathrm{Mg}-\mathrm{Gd}$ alloys with different mass fraction of Gd at different temperatures and found that the elevated temperature strength of $\mathrm{Mg}-20 \% \mathrm{Gd}$ alloy is superior to that of the traditional WE54A heat-resistant magnesium alloys. Binary Mg-Gd alloys have also been reported to have a creep resistance superior to that of alloys WE43 and QE22 in terms of steady-state creep rates ${ }^{[12]}$. Meanwhile, a lot of researches have been developed about adding Sc, Y, Nd ect. rare-earth elements on the basis of Mg-Gd binary alloys, in order to decrease the density and costing and improve the mechanical properties $^{[2-8]}$. However, these researches mainly focus on the improvement of mechanical properties and there are few works reported on the solidification behavior of the $\mathrm{Mg}-\mathrm{Gd}$ binary alloys under different casting conditions.

The objective of the present study is to investigate the microstructures and microsegregations of $\mathrm{Mg}-1.5 \mathrm{Gd}$ alloy and to establish the relationship between characteristic length scales and growth processing parameters quantitatively under controlled directional solidification conditions, which can enable us to predict the microstructure of this alloy system.

\section{Experiment}

$\mathrm{Mg}-1.5 \mathrm{Gd}$ alloy was prepared from pure $\mathrm{Mg}(99.98 \%)$ and Mg-28Gd (wt\%) master alloy by melting in an electricalresistance furnace under the protection of anti-oxidizing flux. The melts were poured into an iron test bar mould (preheated to 
200 300 ${ }^{\circ} \mathrm{C}$ ) at about $740{ }^{\circ} \mathrm{C}$. Then, the test bars were further processed into the samples of $\Phi 7.8 \mathrm{~mm} \times 90 \mathrm{~mm}$ for subsequent directional solidification experiments.

A high temperature gradient Bridgman-type directional solidification furnace with a graphite heater and quenching system of water-cooled Ga-In-Sn liquid metals was used. The prepared sample $(\Phi 7.8 \mathrm{~mm} \times 90 \mathrm{~mm})$ was loaded in a special stainless tube crucible with $10 \mathrm{~mm}$ outer diameter (OD), $8 \mathrm{~mm}$ inner diameter (ID), $120 \mathrm{~mm}$ in length and sealed ends, which was designed to prevent the oxidation of the alloy ${ }^{[13]}$. The crucible was put in the vacuum furnace with the graphite heater, pumped down to $1.1 \mathrm{~Pa}$, backfilled with high-purity $\mathrm{Ar}_{2}$ gas, and then heated to $800{ }^{\circ} \mathrm{C}$ for $30 \mathrm{~min}$. When the axial temperature gradient reached $40 \mathrm{~K} / \mathrm{mm}$, the sample was directionally solidified by moving the crucible downward at a given speed $(10 \sim 200 \mu \mathrm{m} / \mathrm{s}$ ) for about $40 \mathrm{~mm}$, and then quenched in Ga-In-Sn liquid metals. In the analysis, the withdrawal rate was approximately used as the growth rate.

For subsequent characterization, the solidified samples were cut along both the longitudinal and transverse sections to investigate the quenched interface morphology and the solidification microstructure. Olympus PM-G3 type optical microscope (OM) and JEOL JSM-5800 type scanning electron microscope (SEM) were used to examine the solidification microstructure. The phase analysis was conducted in an Oxford Inca type X-Ray energy dispersive spectroscope (EDS). The $\mathrm{X}$-ray diffraction (XRD) was performed on a X'Pert PRo MPD type instrument in the diffraction angle $(2 \theta)$ range between $20^{\circ}$ and $90^{\circ}$, using $\mathrm{Cu} \mathrm{K \alpha}(\lambda=0.154 \mathrm{~nm})$ as a radiation source. The volume fraction of the second phase was measured by Image-Pro Plus 6.0 (Media Cybernetics, Inc., Bethesda, MD).

\section{Results and Discussion}

\subsection{Phase diagram and solidification path calculation}

Fig.1a shows the equilibrium phase diagram of the $\mathrm{Mg}-\mathrm{Gd}$ binary system calculated by the thermodynamic calculation software Thermo-Calc ${ }^{[14]}$. It can be seen that only $\alpha(\mathrm{Mg})$ phase is formed during the cooling process in the equilibrium condition (the dash line in Fig.1a).

The calculated solidification path of $\mathrm{Mg}-1.5 \mathrm{Gd}$ alloy using Scheil model, which is based on the assumption of complete mixing in the liquid but no diffusion in the solid, is shown in Fig.1b. The sequence of phase formation is as follows: Liquid $\rightarrow$ Liquid $+\alpha(\mathrm{Mg}) \rightarrow$ Liquid $+\alpha(\mathrm{Mg})+\mathrm{Mg}_{5} \mathrm{Gd} \alpha(\mathrm{Mg})+\mathrm{Mg}_{5} \mathrm{Gd}$. The ultimate phases consist of primary $\alpha(\mathrm{Mg})$ phase and binary eutectic $\alpha(\mathrm{Mg})+\mathrm{Mg}_{5} \mathrm{Gd}$ phase which is formed at $556^{\circ} \mathrm{C}$.

\subsection{Phase identification}

Fig.2 shows the XRD analysis results of the experimental alloy prepared by the directional solidification with various growth rates. It can be seen that only $\alpha(\mathrm{Mg})$ phase and $\mathrm{Mg}_{5} \mathrm{Gd}$ phase are found in the alloy, which is in good agreement with the calculated result of Scheil model. The SEM microstructures of the experimental alloy at growth rate of $10 \mu \mathrm{m} / \mathrm{s}$ are given
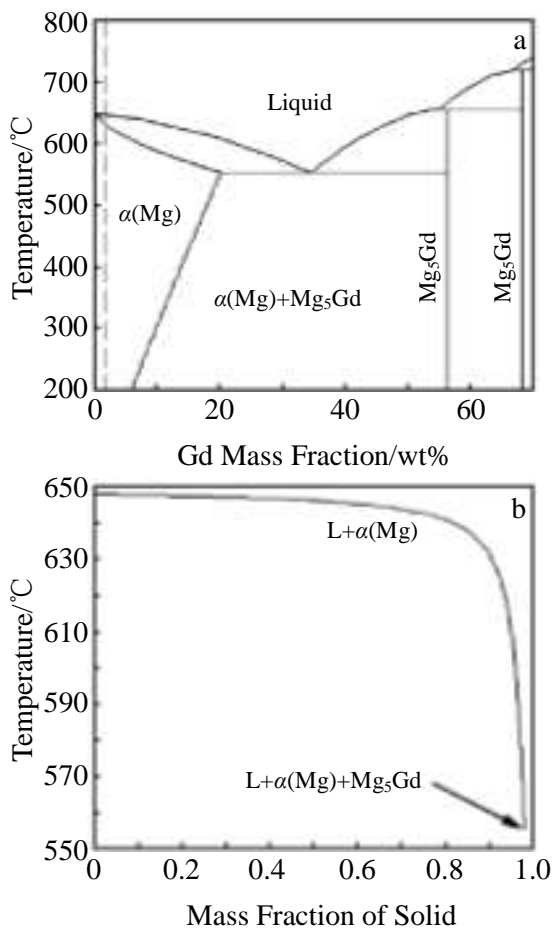

Fig.1 Equilibrium phase diagram of Mg-Gd binary system (a) and calculated solidification path of Mg-1.5Gd alloy using Scheil model (b)

in Fig.3a and 3b. It is noted that two portions are observed: the black portion presents typical cellular morphology and the white portion distributes along the grain boundary. The EDS results confirm that the black portion is $\alpha(\mathrm{Mg})$ matrix phase and the white portion is $\alpha(\mathrm{Mg})+\mathrm{Mg}_{5} \mathrm{Gd}$ binary eutectic phase, as shown in Fig.3c and 3d.

Meanwhile, the volume fractions of the eutectic phase were measured for the samples with different growth rates, shown in Table 1. The values calculated by Scheil model are also shown in the same table. It is found that the experimental values of eutectic phase fractions decrease with the increase of growth rate while that calculated by Scheil model are constant and the

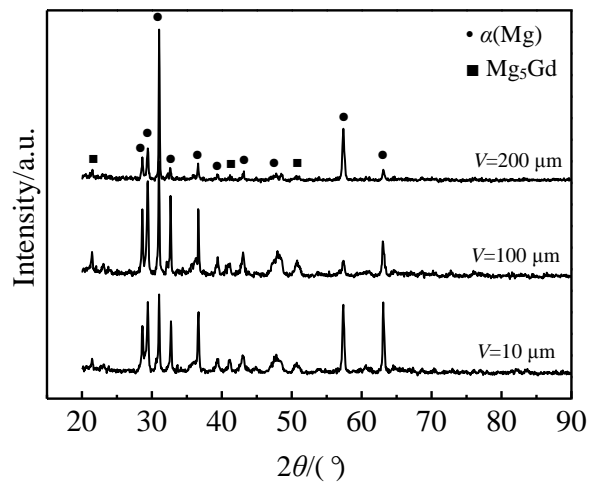

Fig.2 XRD patterns of the directional solidifying experimental alloy under $G=40 \mathrm{~K} / \mathrm{mm}$ at different growth rates 


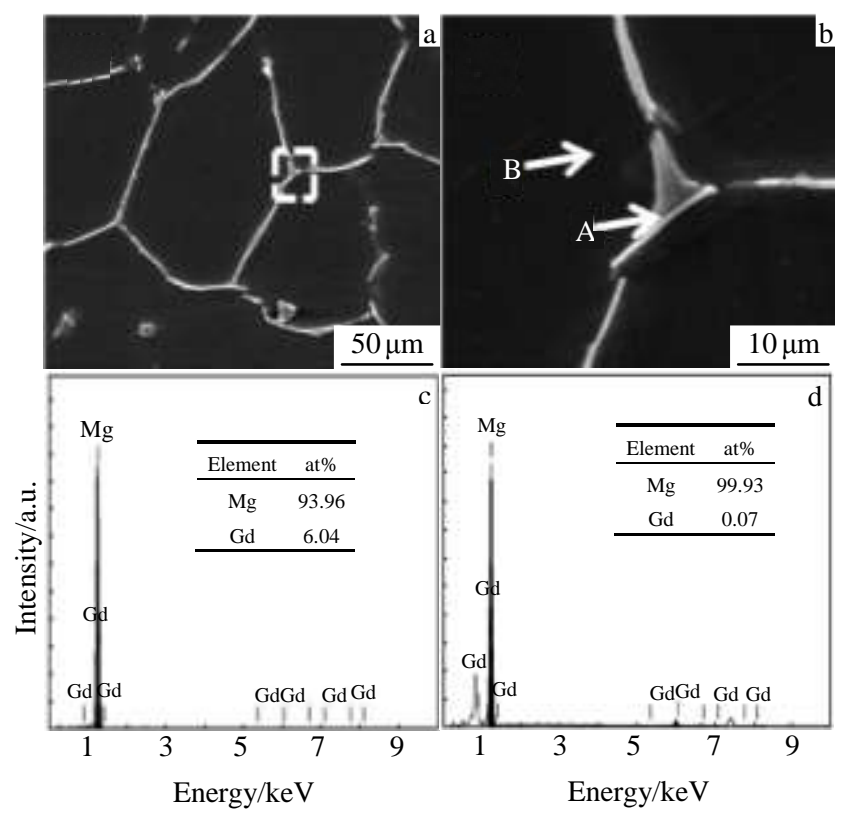

Fig.3 SEM images of the experimental alloy under $G=40 \mathrm{~K} / \mathrm{mm}$ at growth rate of $10 \mu \mathrm{m} / \mathrm{s}(\mathrm{a}, \mathrm{b})$ and corresponding EDS results of point A (c), and point B (d) in Fig.3b

calculated values are higher than the experimentally measured values. This is mainly because the Scheil model ignores the back diffusion of alloying elements during the solidification.

\subsection{Directional solidification microstructures}

Optical microstructures of the directional solidifying $\mathrm{Mg}$ $1.5 \mathrm{Gd}$ alloy under the constant temperature gradient $40 \mathrm{~K} / \mathrm{mm}$ at different growth rates are presented in Fig.4. It can be seen that $\alpha(\mathrm{Mg})$ exhibits a typical cellular structure with coarse trunks along longitudinal section and regular cellular structure on transversal section.

It is well known that the cellular spacing has a significant effect on the mechanical properties such as yield strength and creep resistance of the alloy. Numerical models were proposed by Hunt ${ }^{[15]}$, Kurz and Fisher ${ }^{[16]}$ and Trivedi ${ }^{[17]}$ to characterize the cellular spacing under different solidification conditions as a function of $C_{0}, G$ and $V$, which are given by Eqs.(1) (3) respectively:

$\lambda=2.83[m(k-1) D \Gamma]^{0.25} C_{0}^{0.25} V^{0.25} G^{-0.5} \quad$ (Hunt model)
$\lambda=4.3\left[m(k-1) D \Gamma / k^{2}\right]^{0.25} C_{0}^{0.25} V^{0.25} G^{-0.5}$ (Kurz-Fisher model)
$\lambda=2.83[m(k-1) D \Gamma L]^{0.25} C_{0}^{0.25} V^{0.25} G^{-0.5}$ (Trivedi model) $\lambda=2.83[m(k-1) D \Gamma L]^{0.25} C_{0}^{0.25} V^{0.25} G^{-0.5}$ (Trivedi model)
where, $\Gamma$ is the Gibbs-Thomson coefficient, $m$ is the liquids line slope, $k$ is the partition coefficient, $C_{0}$ is the initial alloy composition, $D$ is the diffusion coefficient in the liquid, $L$ is a constant with the value of 28 that depends on harmonic perturbations. Thermophysical parameters of $\mathrm{Mg}-1.5 \mathrm{Gd}$ alloy used in calculations for the models are given in Table 2 .

The experimental values of cellular spacing of the experimental alloy are shown in Table 3 . It can be seen that the cellular spacing $\lambda$ decreases with the increase of growth rate $V$.
Table 1 Experimental measured and thermodynamically calculated volume fractions of the eutectic phase in Mg-1.5Gd alloy

\begin{tabular}{ccc}
\hline \multirow{2}{*}{$\begin{array}{c}\text { Growth rate, } \\
V / \mu \mathrm{m} \cdot \mathrm{s}^{-1}\end{array}$} & \multicolumn{2}{c}{ Eutectic volume fraction/vol\% } \\
\cline { 2 - 3 } & $\begin{array}{c}\text { Image analysis } \\
\text { results }\end{array}$ & $\begin{array}{c}\text { Calculation results } \\
\text { by Scheil model }\end{array}$ \\
\hline 10 & 1.06 & 1.19 \\
40 & 1.01 & 1.19 \\
100 & 0.89 & 1.19 \\
200 & 0.73 & 1.19 \\
\hline
\end{tabular}
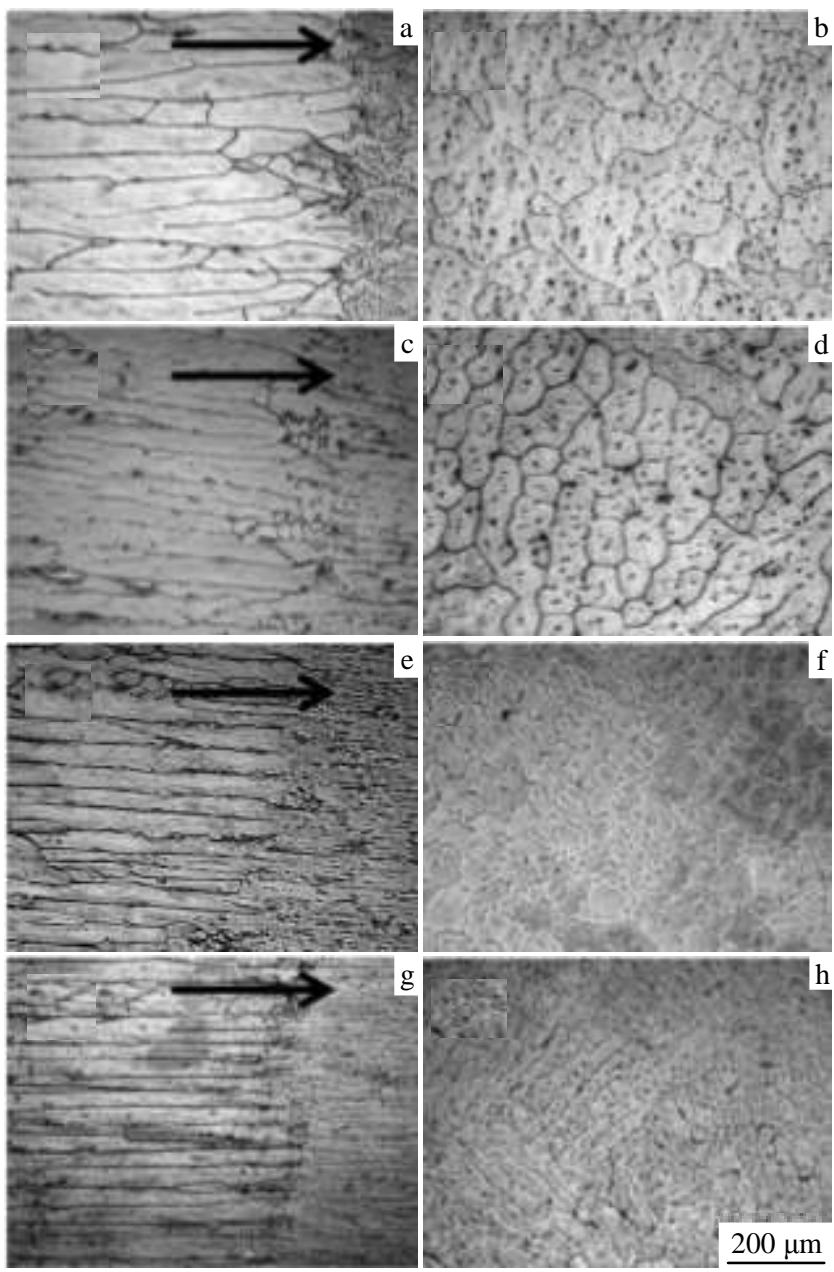

Fig.4 OM microstructures of the directional solidifying experimental alloy under $G=40 \mathrm{~K} / \mathrm{mm}$ at different growth rate: (a, b) 10 $\mu \mathrm{m} / \mathrm{s}$, (c, d) $60 \mu \mathrm{m} / \mathrm{s},(\mathrm{e}, \mathrm{f}) 150 \mu \mathrm{m} / \mathrm{s}$, and $(\mathrm{g}, \mathrm{h}) 200 \mu \mathrm{m} / \mathrm{s}$

Table 2 Thermophysical parameters of Mg-1.5Gd alloy

\begin{tabular}{ccccc}
\hline Parameter & Symbol & Unit & Value & Ref. \\
\hline Initial composition & $C_{0}$ & $\mathrm{wt} \%$ & 1.5 & \\
Slope of liquid line & $m$ & $\mathrm{~K} / \mathrm{wt} \%$ & -1.274 & \\
Distribution coefficient & $k$ & - & 0.0993 & \\
Diffusion coefficient (Liquid) & $D$ & $\mathrm{~cm}^{2} / \mathrm{s}$ & $1.233 \times 10^{-9}$ & {$[18]$} \\
Gibbs-Thomson coefficient & $\Gamma$ & $\mathrm{m} \cdot \mathrm{K}$ & $1.1 \times 10^{-7}$ & {$[18]$} \\
\hline
\end{tabular}


Table 3 Experimental and calculated values of cellular spacing of Mg-1.5Gd alloy

\begin{tabular}{ccccc}
\hline $\begin{array}{c}V / \\
\mu \mathrm{m} \cdot \mathrm{s}^{-1}\end{array}$ & $\begin{array}{c}\lambda / \mu \mathrm{m} \\
(\text { Exp. })\end{array}$ & $\begin{array}{c}\lambda / \mu \mathrm{m} \\
\text { (Hunt) }\end{array}$ & $\begin{array}{c}\lambda / \mu \mathrm{m} \\
(\text { Kurz-Fisher) }\end{array}$ & $\begin{array}{c}\lambda / \mu \mathrm{m} \\
(\text { Trivedi) }\end{array}$ \\
\hline 10 & 77.09 & 31.10 & 149.97 & 71.54 \\
40 & 55.65 & 21.99 & 106.05 & 50.59 \\
60 & 52.13 & 19.87 & 95.82 & 45.71 \\
100 & 45.33 & 17.49 & 84.36 & 40.23 \\
150 & 40.37 & 15.81 & 76.23 & 36.36 \\
200 & 35.38 & 14.71 & 70.90 & 33.83 \\
\hline
\end{tabular}

The date from Table 3 are plotted in Fig.5. It can be seen that the relationship between $\log \lambda$ and $\log V$ are essentially linear for the growth velocity. Through linear regression analysis, the relationship between $\lambda$ and $V$ under the temperature gradient of $40 \mathrm{~K} / \mathrm{mm}$ was established as follows:

$$
\lambda=130.2827 \mathrm{~V}^{0.2228}
$$

In additional, the values of cellular spacing calculated by the Hunt model, the Kurz-Fisher model, and the Trivedi model are also given in Fig.5. It can be seen that the values calculated by Kurz-Fisher model and Hunt model obviously diverge from the measured results, while the measured results are in good agreement with the values calculated by Trivedi model. However, we can not ignore that there still exist a little of deviations between the calculations and the experimental results, since the directional solidification was carried out on the stainless tube crucible with lower thermal conductivity $(0.16 \mathrm{~W} / \mathrm{cm} \cdot \mathrm{K})$ compared with that of pure magnesium melt $(1.56 \mathrm{~W} / \mathrm{cm} \cdot \mathrm{K})^{[15]}$. Thus the stainless pipe wall may obstruct the heat spreading and coarsen the trunk of the cellular spacing. Meanwhile, some experimental errors, such as, solidification parameter errors and spacing measurement errors may also cause the deviation of experimental results from the prediction of theories models.

\subsection{Microsegregation}

Microsegregation has a significant effect on the properties of the alloys, such as the inhomogeneous precipitation, fatigue behavior and corrosion resistance ${ }^{[19]}$. Fig.6 shows the BSE images and the EPMA maps of $\mathrm{Mg}$ and $\mathrm{Gd}$ elements in the $\mathrm{Mg}-1.5 \mathrm{Gd}$ alloy prepared from samples with the growth rate of 30 and $200 \mu \mathrm{m} / \mathrm{s}$. It can be seen that most of Gd element are concentrated along the grain boundary formed at the end of solidification while $\mathrm{Mg}$ is mainly distributed in the grain interior.

Fig.7 shows the measured concentration profile of $\mathrm{Gd}$ as a function of solid fraction at the growth rates of 10, 100 and 200 $\mu \mathrm{m} / \mathrm{s}$. It reveals that the Gd content increases gradually as the solidification proceeds but increases abruptly at the formation of the $\mathrm{Mg}_{5} \mathrm{Gd}$ phase. As shown in the same figure, the concentration profile of Gd was also calculated using Scheil model. It is noted that the measured concentration profile of $\mathrm{Gd}$ for three growth rates agree reasonably with the calculation one.
It is also noted that such agreement is connected with the growth rate. The measured concentration profile of $\mathrm{Gd}$ for the growth rate of $200 \mu \mathrm{m} / \mathrm{s}$ agrees better with the calculation one than that for the growth rates of 10 and $100 \mu \mathrm{m} / \mathrm{s}$. This is due to the influence of back-diffusion of alloying element decreasing with the increase of growth rate while in Scheil model backdiffusion is ignored. Thus, it is indicated that the microsegregation of alloying element $\mathrm{Gd}$ in the $\mathrm{Mg}-1.5 \mathrm{Gd}$ alloy prepared by directional solidification can be described by Scheil model with accuracy.

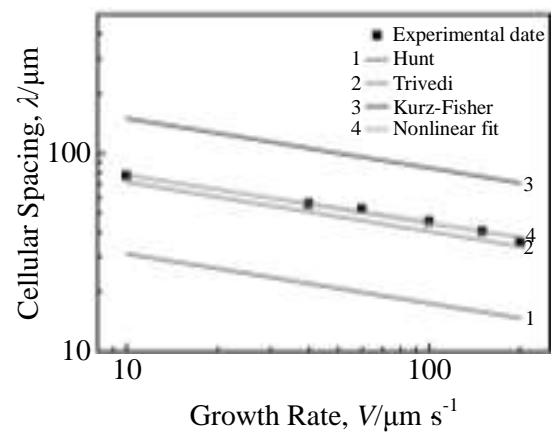

Fig.5 Comparison of observed cellular spacing with the predictions of different theory models

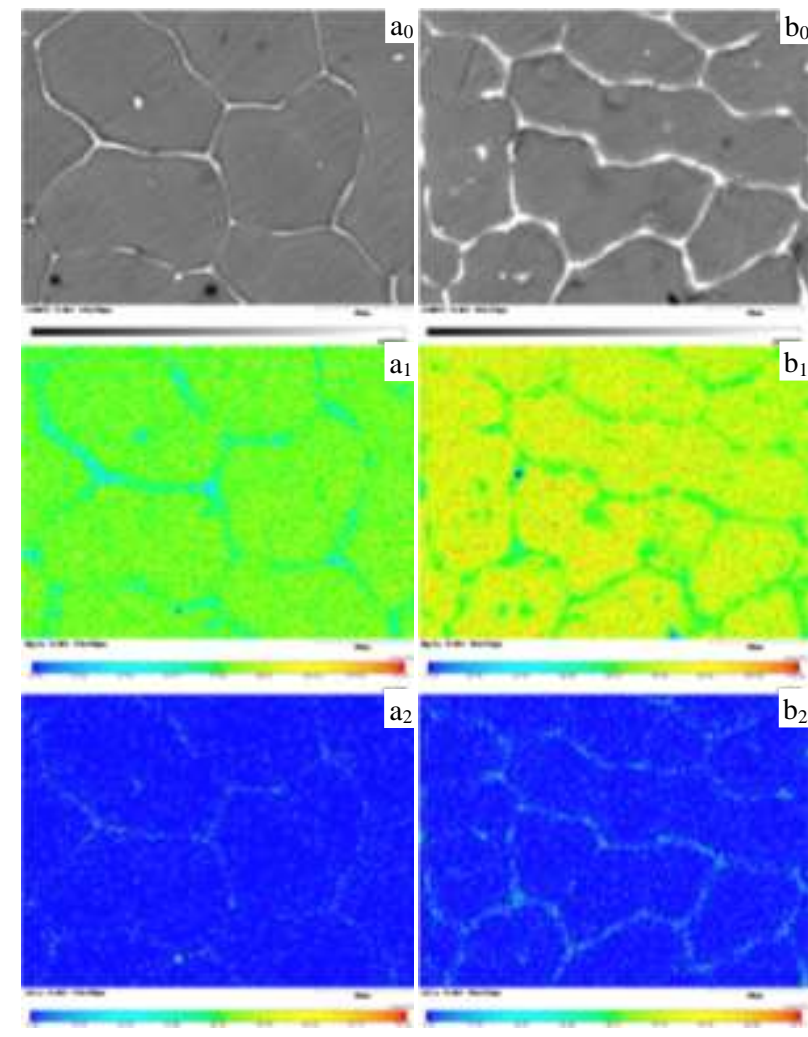

Fig.6 EPMA backscatter images $\left(\mathrm{a}_{0}, \mathrm{~b}_{0}\right)$ and $\operatorname{Mg}\left(\mathrm{a}_{1}, \mathrm{~b}_{1}\right), \mathrm{Gd}\left(\mathrm{a}_{2}, \mathrm{~b}_{2}\right)$ distribution maps of the directional solidifying experimental alloy under $G=40 \mathrm{~K} / \mathrm{mm}$ at $30 \mu \mathrm{m} / \mathrm{s}$ (a) and $200 \mu \mathrm{m} / \mathrm{s}$ (b) 


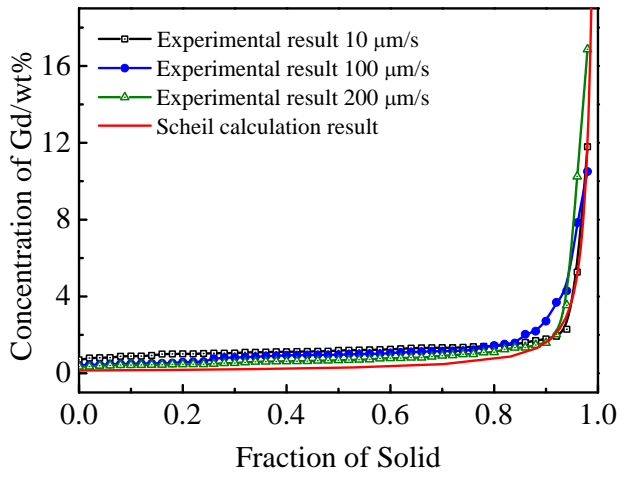

Fig.7 Microsegregation of $\mathrm{Gd}$ in the directional solidifying experimental alloy under $G=40 \mathrm{~K} / \mathrm{mm}$ at different growth rates

\section{Conclusions}

1) The directionally solidified $\mathrm{Mg}-1.5 \mathrm{Gd}$ alloy is mainly consisted of primary $\alpha(\mathrm{Mg})$ phase and $\alpha(\mathrm{Mg})+\mathrm{Mg}_{5} \mathrm{Gd}$ binary eutectic phase, which agrees well with the prediction of Scheil model.

2) The primary $\alpha(\mathrm{Mg})$ phase exhibits a typical cellular structure and the cellular spacing $\lambda$ can be expressed as a function of growth rate $V$ in the form: $\lambda=130.2827 V^{0.2228}$ by a linear regression analysis under a constant temperature gradient (40 K/mm) at the growth rate between 10 200 $\mu \mathrm{m} / \mathrm{s}$.

3) The experimental cellular spacing values are in good agreement with the cellular spacing values calculated by Trivedi model but largely diverge from that calculated by Hunt model and Kurz-Fisher model.

4) The microsegregation of Gd in the directionally solidified Mg-1.5Gd alloy measured by EPMA agrees reasonably with the results predicted by the Scheil model, suggesting that the Scheil model can be used for predicting the microsegregation of cast magnesium alloys.

\section{References}

1 Yang Z, Li J P, Zhang J X et al. Acta Metall Sin, Engl Lett[J], 2008, 21(5): 313

2 Wang J, Meng J, Zhang D P et al. Mater Sci Eng A[J], 2007, 456: 78

3 Gao L, Chen R S, Han E H. J Alloy Compd[J], 2009, 481: 379

4 Nie J F, Gao X, Zhu S M. Scripta Materialia[J], 2005, 53: 1049

5 Michiaki Y, Tsutomu A, Shintaro Y et al. Scripta Materialia[J], 2005, 53: 799

6 Ifeanyi A A, Shigeharu K, Yo K. Mater Trans[J], 2001, 42(7): 1212

7 Yi Jianlong, Zhang Xinming, Ma Guang et al. Rare Metal Materials and Engineering [J], 2009, 38(10): 1852 (in Chinese)

8 Wang Ping, Liu Daoxin, Li Jianping et al. Rare Metal Materials and Engineering[J], 2011, 40(6): 995 (in Chinese)

9 Drits M E, Sviderkaya Z A, Rokhlin L L et al. Metallovedenie Termicheskaya Obrabotka Metallov[J], 1979, 11: 62

10 Rokhlin L L, Nikitina N I. Fizika Metallov Metallovedenie[J], 1986, 62(4): 781

11 Shigeharu K, Shigeru I, Kiyoaki O et al. Journal of Japan Institute of Light Metals[J], 1992, 42(12): 727

12 Mordike B L. Mater Sci Eng A[J], 2002, A324: 103

13 Liu S J. China Patent, 201310014615.5[P]. 2013

14 Andersson J O, Helander T, Höglund L et al. Thermo-Calc and DICTRA, Computational Tools for Materials Science[M]. Calphad, 2002, 26: 273

15 Hunt J D. Solidification and Casting of Metals[M]. London: The Metal Society, 1979: 3

16 Kurz W, Fisher D J. Acta Metall[J], 1981, 29: 11

17 Trivedi R. Metall Trans A[J], 1984, 15: 977

18 Kurz W, Fisher D J. Fundamentals of Solidification[M]. Switzerland: Trans Tech Publications, 1998

19 Zhang C, Ma D, Wu K S et al. Science Direct Intermetallics[J], 2007, 15: 1395

\title{
不同速率定向凝固条件 Mg-1.5Gd 镁合金的微观结构及微观偏析
}

\author{
王甲安 ${ }^{1}$, 王甲贺 ${ }^{2}$, 宋忠孝 ${ }^{3}$ \\ (1. 华电电力科学研究院, 浙江 杭州 310030)
}

(2. 西北工业大学 凝固技术国家重点实验室, 陕西 西安 710072)

(3. 西安交通大学, 陕西 西安 710049)

摘 要: 研究了在定向凝固条件下凝固速率对 Mg-1.5Gd 镁合金微观结构的影响。试样通过 Bridgman 定向凝固炉来制备, 温度梯度恒定 为 $40 \mathrm{~K} / \mathrm{mm}$, 凝固速率为 10 200 $\mu \mathrm{m} / \mathrm{s}$ 。研究发现, $\mathrm{Mg}-1.5 \mathrm{Gd}$ 镁合金凝固组织为典型胞晶结构, 通过线性拟合得到胞晶间距 $(\lambda)$ 与凝固速 率 $(V)$ 关系为: $\lambda=130.2827 V^{0.228}$, 此结论与 Trivedi 模型拟合较好。通过 Scheil 模型进行热力学凝固路径计算, 结合试验观察可以确定凝 固组织为 $\alpha(\mathrm{Mg})$ 相和 $\alpha(\mathrm{Mg})+\mathrm{Mg}_{5} \mathrm{Gd}$ 二元共晶相。同时, 通过 Scheil 模型计算所得的 $\mathrm{Gd}$ 元素的微观偏析与 EPMA 测量结果基本一致。 关键词: $\mathrm{Mg}-1.5 \mathrm{Gd}$ 二元合金; 定向凝固; 微观结构; 胞晶间距; 微观偏析 